\title{
LA FUNDACIÓN DE CIRENE EN LAS ODAS DE PÍNDARO
}

\author{
Aida Míguez Barciela
}

HERCRITIA

Como es sabido, eso que retrospectivamente llamamos «poesía» no es en Grecia de manera básica texto para leer, sino un decir que se ejecuta de una u otra manera y en una u otra ocasión. Los epinicios de Píndaro se cantan y se bailan en ocasión de la victoria de alguien en unos juegos competitivos. En este momento, «oralidad» es el término no marcado, mientras que «escritura» es el término marcado; lo obvio es que un poema sea oral, pero no como elección frente a escrito. Que los poemas se escriban tampoco quiere decir que pasen a ser textos para leer, sino simplemente que se conservan mediante la escritura. El texto es más bien algo así como la partitura de una canción que ya no oímos, el guión de una película que se ha desvanecido para siempre.

Pasando al análisis de la forma de los epinicios, distinguiremos dos modos de decir en cuya interacción se pone de manifiesto un problema que luego se verá en el plano de los contenidos. Llamaremos «discurso» a ese tipo de decir que emplea formas personales: yo, tú, verbos con marca de actualidad, así como los deícticos cuya referencia depende del uso de estas voces (el aquí-ahora de la performance). «Relato», en cambio, es el decir en tercera persona (o la no-persona) que emplea verbos con marca de pretérito; los deícticos tienen en este caso un valor derivado: entonces (tiempo no-ahora), allá (noaquí). El poema homérico consiste ante todo en un relato. El yo desaparece y enseguida pasa a tratarse de él, ellos, ella: Crises, Agamenón, los aqueos. El poema no dice el yo, no se recrea en la fuente del decir; lo que se dicen son las cosas, en todo su esplendor, en todo su brillo, en todo su detalle. El poema de Píndaro combina elementos discursivos y elementos narrativos, y la cuestión a dilucidar es cómo se comportan exactamente estos dos tipos de elementos. Por de pronto, los elementos discursivos cumplen la función de interrumpir o abandonar o romper con las partes narrativas del poema. Esto quiere decir que si el poema alude en un momento a cierta historia, o incluso la elabora en un grado tal que se genera lo que a veces llamamos ilusión estética, siempre llega el momento en que algo externo, un yo que habla, un apóstrofe a un tú, rompe la ilusión, cancela la historia, 
nos devuelve al aquí-ahora de la performance, hace evidente la condición de canto del canto, dice y se recrea en el decir dentro del decir. La inmersión en el relato se suspende continuamente en la oda de Píndaro. La ilusión se rompe una y otra vez por lo mismo que el decir se dice a sí mismo una y otra vez.

Los elementos discursivos, por ejemplo las paremias, los deícticos, las invocaciones a la musa y las autorreferencias, producen una y otra vez distancia frente al relato, impiden la inmersión en una historia, interrumpen la presentación de cosas que constituye la forma básica del decir. El épos, la maestría básica en el decir hace aparecer cosas, genera eso que a veces se llama enárgeia: viveza, claridad, presencia de unas y otras y otras cosas. Justamente porque rompe una y otra vez con la presentación de cosas, la oda de Píndaro se mueve en una constante distancia frente al épos. El poema que se dice a sí mismo es el mismo que rompe una y otra vez con ese modo de decir que hemos llamado relato, cuyo exponente más importante y más irrenunciable es Homero. Así pues, en el plano de la forma, Píndaro se sitúa en una distancia, ruptura, apartamiento o lejanía frente al épos.

\section{PÍTICA NOVENA}

P. 9 comienza con un verbo en primera persona: quiero... proclamar varón feliz a Telesícrates. Un yo es lo primero que se hace presente en el canto; estamos, pues, ante un comienzo discursivo y autorreferente. El movimiento de la oda del discurso al relato se produce mediante un así llamado deslizador, en este caso un pronombre demostrativo en acusativo. Por su victoria en los juegos, Telesícrates es corona de Cirene; a continuación se dice que a ésta (sc. Cirene) el de pelo ondulante, el hijo de Leto, la raptó una vez de los pliegues del monte Pelión. El deslizador nos sitúa de pronto en el interior de un relato acerca de una figura femenina raptada por Apolo. No solo pasamos al decir en tercera persona, sino que la actualidad se abandona para entrar en el «una vez» de cierta historia. También nos situamos en un espacio distinto: los pliegues del Pelión. Una vez aquí se precisa un poco más quién es Cirene: la virgen salvaje que Apolo lleva en el carro. La parthénos agrotéra es la virgen que pertenece al agrós, no al espacio urbano, sino al espacio rural o silvestre o salvaje. Todos estos datos conectan entre sí. Primero, el entorno geográfico: no se ha mencionado ninguna pólis, sino solamente valles y montañas, lo cual profundiza en la condición agrotéra de Cirene. Concordando con la topografía está la referencia a divinidades primordiales, divinidades preolímpicas (en el fondo genealógico de Cirene se descubren un río y una náyade). El orden político y el orden olímpico conectan entre sí. Allí donde no hay pólis tampoco hay olímpicos. Nos referiremos a la cuestión de los olímpicos al comentar la P. 5. Por el momento basta con retener la condición antecedente de las divinidades implicadas en la genealogía de Cirene, el propio espacio montañoso (dominado no por hombres sino por bestias), así como la exégesis del carácter «agreste» en la descripción que viene a continuación.

Cirene no amaba los caminos de los telares, ni las comidas con las compañeras de la casa, sino que con flechas de bronce y la espada se esforzaba destruyendo fieras. O sea: 
anormalidad, monstruosidad, rechazo de la casa, de la domesticidad, así como de las actividades femeninas asociadas (tejer es lo que normalmente hacen en casa las mujeres). Después de esta presentación, el epinicio enfoca un episodio singular: Cirene luchaba sola y sin armas con un león enorme en las gargantas de los montes umbríos. Apolo la descubrió en su escondite y admiró su fuerza, admiró su cabeza, que no temblaba, admiró su corazón, que superaba el cansancio y la fatiga, y admiró su pensamiento, que no se dejaba estremecer por el miedo.

Esta admiración de Apolo (el prestar atención el dios a la virgen que actúa de forma aberrante y monstruosa) pondrá en marcha algo. Lo que la mirada de Apolo pone en marcha es el rapto (el arrancar, el separar) de Cirene desde este entorno y esta forma de vida. La intervención erótica de Apolo produce así un tránsito desde el territorio inculto de valles y montañas al territorio cultivado en el que se va a fundar la pólis. Después de atravesar la distancia del mar, se anuncia que los novios llegan al jardín de Zeus en el continente nuevo, es decir, llegan no a un recinto inculto asociado con divinidades preolímpicas, sino al terreno cultivado relacionado con el dios en el que se resume el problema de los olímpicos. Hay continuidad entre la empresa erótica y la empresa política. No en vano después del diálogo con Quirón Cirene ya no es más una virgen escondida en las gargantas sombrías, sino el comienzo de una pólis. La mirada de Apolo no solo descubre, sino que transforma y, en cierto modo, aniquila a Cirene: después de esta mirada, la virgen desaparece, y lo que hay es más bien el territorio en el que se proyecta la fundación de la pólis por colonos procedentes de las islas, colonos reunidos precisamente por Apolo ${ }^{1}$.

Apolo instiga las fundaciones, es el dios fundador, el que guía a los colonizadores hacia la pólis nueva, la pólis que aún no existe. Como es sabido, el verbo que solemos traducir por «fundar» es ktízein. La palabra tiene que ver con la sombra de los bosques en los que se ha dicho que habita Cirene, pues lo que este verbo menciona es justamente el despejar la oscuridad inherente a estos espacios: ktízein significa desbrozar, desmontar, clarear el bosque y la maleza: romper la hýle, abrir la hýle, conquistar un espacio de claridad, despejar la oscuridad que caracteriza al bosque y la espesura; liberar un terreno para el cultivar y el residir. Una isla «bien fundada» es una isla bien despejada y bien cultivada, es decir, la isla que ha sido acondicionada de tal modo que es posible instalarse en ella para vivir. La pólis «bien fundada» es aquélla en la que es posible habitar y residir. Los hombres no habitan en el bosque puro, el bosque inhóspito, sino en una distancia frente a él. Se necesita el desbroce -el despejamiento, la apertura- para que sea posible un residir.

Superar lo agreste de Cirene es un requisito para fundar la pólis. Dejar atrás la hýle -la espesura cerrada, el bosque confuso- es necesario para constituir ese espacio de claridad interna que define la pólis. Ahora bien, esta tarea habitacional es una tarea ambigua, pues abrir el bosque no deja de ser al mismo tiempo destruirlo, no deja de ser a la vez

${ }^{1}$ Cf. mi libro Talar madera. Naturaleza y límite en el pensamiento griego antiguo. La Oficina de Arte y Ediciones, Madrid 2017. 
el principio de deforestación, la ruina de la sombra y la espesura. Pero tiene que haber ruptura, pues de lo contrario la pólis no sería posible. Tiene que haber tala, herida, corte, separación, brecha, pues sin claro abierto en medio del bosque el bosque no sería conocido en absoluto. Sin un «fuera» del bosque no sería posible ver el bosque como bosque, el bosque no sería relevante en absoluto. Se necesita el no-bosque para que haya en verdad el bosque.

Conocer implica distanciarse, exige separarse, exige romper. En los espacios de hýle pura no se ha producido todavía esta separación. Por eso en el bosque no solo no hay pólis, tampoco están presentes los campos de cultivo ni los saberes que ese peregrino que es Odiseo relaciona una y otra vez con la presencia de hombres. Allí donde no hay ni cultivos ni trabajo ni fundaciones tampoco hay hombres, sino más bien monstruos: lotófagos, cíclopes, ninfas, seres que no conocen ni necesitan los cultivos. No hay pólis, sino soledades y espesuras. Y si allí donde no hay ruptura no hay hombres, entonces tal vez el hombre sea el que rompe, el que abre la maleza.

Ahora bien, para que se trate en efecto de abrir un claro en el bosque, para que la claridad sea relevante, el bosque debe ser todavía lo primero. Estamos en la situación en la que no hay el bosque sobre un claro único, sino el claro sobre un bosque que está ya ahí como lo primero. El bosque es todavía lo primero, por eso todavía puede oponer una resistencia poderosa; las fundaciones -las aperturas, las talas, los destroces- todavía no lo han colonizado todo. Esto quizá tenga que ver con el hecho de que Apolo tenga a Ártemis como hermana gemela:

Apolo es el dios de la distancia. En la Ilíada uno de sus epítetos es hekáergos, el que actúa desde la distancia, y hekébolos, el que dispara desde lejos. En consonancia con esto está el elogio de Apolo que en P. 9 pronuncia Quirón. En respuesta a la pregunta del dios acerca de qué procede hacer con Cirene, el centauro ensalza su capacidad de visión, su tremendo y profundo conocimiento: Apolo conoce de todo el fin y todos los caminos, no desconoce cuántas hojas hace brotar la primavera, ni cuántos granos de arena ruedan en el mar y en los ríos. El dios de la distancia es también el dios de las fundaciones: el que envía a los mortales lejos, afuera, a la lejanía. Por eso es a Delfos adonde viajan los que se han quedado sin morada, y por eso es Apolo quien hace de aquéllos que han perdido las conexiones, que han perdido el suelo bajo los pies, las figuras encargadas de fundar una nueva pólis, es decir, de poner en marcha el proyecto de habitar (en) la distancia. Ártemis, por su parte, habita no en la pólis sino en la ignota espesura, en las montañas inaccesibles, en los bosques impenetrables. Ella encarna en cierto modo la (todavía) irreductibilidad del bosque. Pero no solo eso, sino que ella es también quien pone freno a las actividades destructivas (por ejemplo la caza indiscriminada), lo cual no es indiferente a su condición femenina. Hay un freno regulador, y este freno es femenino (el bosque todavía se opone, no ha sido todavía reducido).

Es conocida la resistencia que la ninfa Telfusa opone a los proyectos de Apolo, quien en el Himno a Apolo inicia un viaje que no solo explora por primera vez lugares que no han pisado jamás los pies de los mortales, sino que también transforma eso que 
originalmente era puro bosque, pura espesura, en espacio conocido, espacio político. También aquí el espacio prepolítico resulta ser a la vez un espacio preolímpico: las divinidades que Apolo encuentra en su viaje exploratorio no pertenecen al orden de los olímpicos, por lo mismo que son anteriores a la presencia de altares y santuarios (aquí hay dioses, pero no templos). Ahora bien, aunque la desfigura o la mutila, Apolo no puede eliminar sin más a Telfusa, la diosa que ya está ahí cuando el dios irrumpe, sino que tiene que dialogar o negociar con ella. Encontramos de nuevo una ambigüedad, la misma por la que Apolo tiene a Ártemis como su otra cara: el propulsor de las fundaciones que aclaran la hýle tiene enfrente (o a su lado o detrás) una diosa que protege las criaturas que habitan el bosque y regula las actividades que allí tienen lugar. El impacto de la pólis sobre el bosque es así un impacto ambiguo. Cirene muere en cierto modo al ser arrancada a los valles y los bosques. Telfusa ya no tendrá más que una presencia subterránea: no dominará el lugar, sino que correrá bajo las rocas.

\section{PÍTICA QUINTA}

Vamos a complementar lo dicho hasta aquí observando qué actividades atribuye P. 5 al fundador de Cirene, figura que no tenía protagonismo en P. 9.

P. 5 entra en el detalle de las operaciones que realiza el fundador una vez llega a Libia. ¿Llega desde dónde? En P. 9 se decía que Cirene sería colonizada por isleños reunidos por Apolo. Isleños, esto es, gente que viene de lejos, de la distancia. Los fundadores vienen de la isla, esa tierra que no es ni mar ni es tierra, sino más bien un «entre» el mar y la tierra. La irrupción de Bato comporta que el espacio agreste se limpia o se abre o se despeja (los leones endémicos huyen espantados), así como que lo bárbaro-nativo se supera mediante la lengua extranjera del fundador: el ktistés o el ktístor (dos nombres de agente del verbo ktízein), es decir, el que abre la maleza, rompe la espesura, pone un claro, construye un espacio habitable, etcétera.

Lo que hace el ktístor es organizar el territorio de la pólis. La oda dice que Bato fundó recintos mayores para los dioses. No se necesitan los dioses para constituir un Estado. En el contexto griego antiguo, la tarea de fundar pólis implica en cambio construir una morada para los dioses. De hecho, la historiografía señala que el arranque de eso que llamamos «Grecia» es también el momento de la proliferación de santuarios y templos cuya significación es en gran medida una significación política (la ubicación de los templos sirve, entre otras cosas, para estabilizar y definir el territorio de una pólis), de manera que hay una concomitancia entre la emergencia de la pólis y la tematización de lo divino.

Así pues, el fundador de pólis no solo amuralla un espacio, construye casas para los hombres y reparte lotes de tierra para el cultivo, sino que también funda o construye los recintos de los dioses, operación que no es tanto religiosa como política, es decir, rehúsa la aplicabilidad de nuestras categorías obvias. El reconocimiento de los dioses forma parte del proyecto político. Reconocer los dioses no es un asunto ni privado ni personal; 
es una tarea de la propia pólis. Esto nos pone otra vez ante una ambigüedad. Era ambigua la relación de Apolo con los espacios desiertos y de bosque en los que ponía en marcha sus fundaciones, y es ambigua la operación que la oda atribuye a Bato. Bato funda recintos mayores para los dioses. Por un lado, un recinto es el resultado de un medir, separar y dividir; por otro, el álsos es el lucus, la luz abierta en la oscuridad, el claro en el bosque (el claro es el bosque reconocido como bosque). Es importante reparar en que este medir, separar, delimitar, dividir no obedece a las decisiones del fundador: el fundador no está imponiendo su criterio cuando decide que ahí se construyen los templos o allá se abren los caminos para las procesiones. Esto sería lo que nosotros entenderíamos sin problemas (un espacio indiferente en el que el sujeto corta o divide por donde quiere o le conviene o es más funcional), pero no es lo que está en juego en el problema de la demarcación de recintos para los dioses. Lo que ocurre es más bien que los dioses ya están ahí, los límites están ya en determinados sitios, y lo que hace el fundador es justamente reconocerlos. No ponerlos donde él quiera, sino donde están de suyo. Por eso los recintos que funda Bato son «mayores»: los dioses ya estaban ahí, y lo nuevo, lo que hace el recinto, es reconocer expresamente eso de suyo divino. Y por eso su cortar, medir y dividir no es tanto decisión como reconocimiento.

El que funda la pólis resulta ser así el mismo personaje que hace conocidos los dioses de un cierto lugar. En este sentido, la fundación de recintos sagrados plantea el mismo problema implicado en eso que Heródoto dice que Homero y Hesíodo han hecho, a saber: descubrir los nombres de los dioses, hacer conocidas sus figuras, tematizar sus prerrogativas y sus competencias. En lugar del dios innominado, el dios con nombre y figura precisa. En lugar de los dioses que están en todas partes, los dioses cuya morada ha sido reconocida expresamente mediante la construcción de un espacio determinado. En el álsos, en el recinto, en el santuario, en el claro del bosque, están en verdad los dioses, los dioses son reconocidos. Reconocer explícitamente la presencia de los dioses -lo que hacen tanto el fundador de pólis como el poeta- es esencial para eso: para que los dioses sean en efecto conocidos, para que sepamos dónde están y cómo son, pero a la vez quizá sea también una irreverencia, una transgresión, un sacrilegio, el comienzo de la disolución, tal como descubrir a Cirene suponía en cierto modo perder a Cirene (desaparece la virgen que había antes de la mirada de Apolo). El conocimiento pone en marcha una pérdida, arruina en cierto modo el ser de lo conocido por lo mismo que lo hace conocido (la innominación quizá sea en cambio la cautela de la preservación).

En el caso del recinto «sagrado», la ambigüedad es evidente en tanto que los recintos son, como hemos dicho, delimitaciones, distancias, espacios definidos y acotados claramente. Construir un recinto de los dioses no quiere decir otra cosa que reconocer que «de aquí a aquí» está el dios o habita el dios. Y sin embargo, este reconocimiento problematiza la vigencia de lo sagrado mismo en tanto que con él se inicia una relativización de los límites y las distancias: si decimos que «de aquí a aquí» el espacio es divino y pertenece a un dios, entonces lo de fuera quizá ya no tenga que ver con lo divino, quizá esté disponible para hacer con ello cualquier cosa. Si el dios está en el recinto, 
entonces quizá ya no se encuentre en todas partes. Al situar los dioses expresamente en un lugar, al cometer la impertinencia que consiste en decirlos y nombrarlos y emplazarlos y tematizarlos, empieza a sonar la pregunta por dónde están exactamente los dioses. Es el propio constituir un espacio sagrado lo que crea el espacio profano. Por eso se comprende que sea justamente en la pólis, proyecto que implica, como hemos visto, el dar morada a los dioses construyendo altares y separando recintos, el proyecto en el que los dioses no solo son reconocidos explícitamente, sino también donde perecen. Se dice porque se pierde y se pierde porque se lo dice. La mirada de Apolo descubría, arrancaba al permanecer oculto, pero al mismo tiempo destruía en cierto modo a aquella virgen cazadora.

\section{PÍTICA CUARTA}

P. 4 contiene un largo relato en torno a la expedición de los argonautas. Tras un comienzo discursivo como el que iniciaba P. 9, el epinicio transita, mediante un adverbio de lugar, al interior de cierto relato: Delfos no es solo el lugar donde ha vencido el hombre al que el coro quiere dedicar un canto de elogio, sino también el espacio en el que una vez fue profetizada la condición de oikistér de Bato, figura que ha adquirido protagonismo en P. 5 (el oikistér es el que habita, el que hace posible un oikeîn).

No podemos comentar aquí en detalle ni la profecía de Medea, que engancha con la de la pitia, ni el relato sobre la expedición que sigue. Llamaremos tan solo la atención sobre el hecho de que esa profecía, pronunciada en el tiempo remoto de la empresa de los héroes semidioses que acompañan a Jasón, se sitúa justamente en el paso de la nave ante la isla de Tera, la misma de cuyos habitantes P. 9 decía que Apolo los reuniría en Libia para fundar una pólis nueva. Lo que nos interesa es que Tera, la isla de la que partirá la expedición colonizadora, la matrópolis de Cirene, es ella misma una colonia: una apoikía. El substantivo apoikía corresponde al verbo apoikéo/apoikízo: habitar aparte, lejos. Apoikeo es trasladarse a vivir en un lugar distinto, irse a vivir a otra parte. La apoikía es el resultado de apoikéo. La apoikía es pues una casa lejos de la casa, una casa que no es casa, un hogar para los que han perdido el hogar. Pues bien, la pólis misma tiene el carácter de una apoikía: implica una ruptura, un viaje, una pérdida, una separación, un ganar distancia frente a la casa, un dejar la casa atrás. Un ápoikos es alguien que está lejos, quien temporal o permanentemente no vive en casa. Los ápoikoi son los emigrantes, los exiliados, los desarraigados, los que han perdido la casa, con la libertad para lo nuevo que esto implica. Por eso en las llamadas colonizaciones no se trata tanto de que la polis ya establecida funde después otra polis a su imagen y semejanza, sino que el fundar en la distancia la nueva-otra polis es fenómeno simultáneo, contemporáneo y concomitante con la emergencia de la propia pólis. Los historiadores dicen incluso que fue justamente la proliferación de colonias lo que reforzó o propulsó en gran medida la cristalización de lo que entendemos por pólis. 
La pólis misma implica ese no-estar-ya-en-casa que hemos encontrado en la semántica de la palabra apoikía. En P. 4 la pólis nueva procede de Tera, la cual es ella misma una apoikía, así como de algo (un trozo de tierra africana) que ha zozobrado y se ha perdido en el mar, todo lo cual quizá no sea ajeno al hecho de que el relato acerca de Cirene tenga como fondo la historia de una gran navegación (la empresa nueva, la expedición inaudita de los argonautas) cuyo núcleo consiste en poner distancia frente al origen, romper con las raíces adentrándose en lo desconocido.

Así pues, la distancia (distancia frente a lo cerrado de la casa, distancia frente a la espesura del bosque) es esencial para que haya pólis, proyecto que supone un reconocimiento radical: no de esto o de aquello, sino de lo que hace que esto sea esto y aquello aquello (el reconocimiento de los dioses entraña lo que nosotros llamaríamos un problema ontológico-fundamental). Ya hemos visto la distancia implicada en el traslado ultramarino de Cirene. Aludimos también a la distancia que recorre Bato, la figura capaz de hacer eso tan enorme y desproporcionado como es reconocer a los dioses y asignarles su sitio. Y en otras odas que no hemos comentado aquí, por ejemplo en la O. 7, el fundador es alguien que se ha quedado en el aire, ese que, habiendo cometido un delito contra los propios vínculos, contra sus propias raíces, se ha visto conducido a buscar instalación en un lugar que no es en el fondo lugar alguno: una isla que emerge del mar profundo, Rodas, la novia del sol, la parte del que se ha quedado sin parte, siendo la isla, como hemos dicho, eso que no es tierra ni es mar: la isla flota en el océano, vaga en el desarraigo, y es justo aquí, en el desarraigo, donde el que ha ganado distancia (el asesino, el criminal, el exiliado) pondrá en marcha la tarea desorbitada e impertinente, insolente y sacrílega, la cual resulta ser a la vez esa empresa brillante y clarividente que hace conocidos los dioses, levanta sus moradas, con la posibilidad de pérdida y fuga que este reconocimiento implica. 